Original Research Article

\title{
Antiproteinuric effects of cilnidipine and amlodipine as add on therapy in hypertensive patients with chronic renal disease: a comparative study
}

\author{
Y. Nisha Maheswari ${ }^{1}$, B. Meenakshi ${ }^{1 *}$, V. Ramasubramanian ${ }^{2}$, J. Ezhil Ramya ${ }^{1}$
}

\begin{abstract}
${ }^{1}$ Department of Pharmacology,
${ }^{2}$ Department of Nephrology,

Government Tirunelveli

Medical College, Tirunelveli,

Tamilnadu, India

Received: 05 August 2017

Revised: 23 August 2017

Accepted: 29 August 2017

\section{*Correspondence to: \\ Dr. B. Meenakshi, \\ Email: bmeenakshibala17@ \\ gmail.com}

Copyright: (C) the author(s), publisher and licensee Medip Academy. This is an openaccess article distributed under the terms of the Creative Commons Attribution NonCommercial License, which permits unrestricted noncommercial use, distribution, and reproduction in any medium, provided the original work is properly cited.

\begin{abstract}
Background: Cilnidipine is a dual blocker of L type and $\mathrm{N}$ type calcium channel and dilates both afferent and efferent arterioles. Hence it increases renal blood flow and reduces glomerular pressure ultimately reducing proteinuria. Thus, it may exert renoprotective effects. The present study was designed to compare the antiproteinuric effects of cilnidipine and amlodipine in hypertensive patients with chronic kidney disease as add on therapy to patients on losartan.

Methods: This is a randomized, open label, prospective, parallel group study conducted in the out patient Department of Nephrology. The trial enrolled Diabetic CKD patients with hypertension and with spot urine protein creatinine ratio $(\mathrm{PCR}) \geq 0.2$ who were being treated with $\mathrm{T}$. Losartan $50 \mathrm{mg} /$ day for $>2$ months. The subjects were then randomly assigned to 2 groups to receive either cilnidipine 10-20mg/day (Group A-46) or amlodipine 5-10mg/day (Group B- 50). The drugs were given for a duration of 6 months for each patient. The dose of losartan (50mg/day) was not adjusted throughout the study.

Results: After 6 months, a significant reduction in systolic and diastolic blood pressure was seen in both the groups. The decrease in urinary protein creatinine ratio was significantly higher in cilnidipine group rather than amlodipine group. Thus, cilnidipine exerted greater antiproteinuric effect than amlodipine.

Conclusions: Cilnidipine has antihypertensive effect equivalent to amlodipine but addition of cilnidipine rather than amlodipine to losartan decreased urine protein excretion in diabetic chronic kidney disease patients.
\end{abstract}

Keywords: Amlodipine, Chronic kidney disease, Cilnidipine, Losartan, Proteinuria

\section{INTRODUCTION}

Chronic kidney disease (CKD) comprises of a spectrum of different pathophysiological processes associated with abnormal kidney function and progressive decline in glomerular filtration rate. Diabetic nephropathy is the most common cause of chronic renal failure worldwide. It is mainly due to epidemic increase in obesity, metabolic syndrome and type II diabetes mellitus. Hypertension is the major consequence of chronic renal disease which develops early during the course of the disease. ${ }^{1}$ Uncontrolled hypertension and proteinuria are the most crucial risk factors for rapid progression of kidney disease and development of extrarenal complications such as cardiovascular disease and stroke. ${ }^{2}$ Thus strict control of blood pressure and suppression of proteinuria are the essential goals of antihypertensive therapy in patients with chronic renal disease. The National kidney foundation clinical practice guidelines recommend a blood pressure goal of $<130 \mathrm{mmHg}$ systolic and $<80 \mathrm{mmHg}$ diastolic for all patients with chronic renal disease. ${ }^{3}$

Renin angiotensin inhibitors such as ACE (Angiotensin converting enzyme) inhibitors and ARB (Angiotensin receptor blockers) are the widely recognized renoprotective agents. These agents effectively reduce proteinuria than any other antihypertensive agents. ${ }^{4}$ 
According to Japanese Society of Hypertension guidelines they are recommended as first choice treatment for hypertensive patients with $\mathrm{CKD}^{5}$ But sometimes it is difficult to achieve satisfactory decrease in proteinuria and blood pressure with these agents alone. ${ }^{6}$ Combination therapy with two or more antihypertensive agents are often required to reduce blood pressure to target levels in these patients. $^{7}$

Dihydropyridine calcium channel blockers are one of the main candidates for combination with RAS (Renin Angiotensin System) inhibitor because they reduce BP in patients who are resistant to other antihypertensive agents. ${ }^{8}$ But the effect of these drugs on proteinuria is inconsistent. Traditional CCB (Calcium channel blocker) like amlodipine act by blocking $\mathrm{L}$ type calcium channel leading to dilatation of afferent arteriole with no effect on efferent arteriole. Ultimately renal blood flow and glomerular pressure increase accelerating proteinuria. ${ }^{9}$ Recently developed CCB like cilnidipine is a dual blocker of $\mathrm{L}$ type and $\mathrm{N}$ type calcium channel and thereby dilates both afferent and efferent arterioles. Hence renal blood flow increases without any increase in glomerular pressure reducing proteinuria. ${ }^{6}$

Renoprotective effects of L - type blockers are considered less than dual $\mathrm{L} / \mathrm{N}$ type blockers. There is still lack of clinical trials comparing renoprotective effects of various calcium channel blockers added to RAS inhibitors which are the first line agents. Thus, the present study was designed to compare the antiproteinuric effects of cilnidipine and amlodipine in hypertensive patients with chronic kidney disease as add on therapy to patients on losartan.

\section{METHODS}

\section{Patients and protocol}

This is a randomized, open label, prospective, parallel group study conducted in the out patient Department of Nephrology. The study was approved by Instituitional Ethical Committee of Tirunelveli Medical College. Informed consent was obtained from each patient. The trial enrolled Diabetic CKD patients with hypertension and with spot urine protein creatinine ratio $(\mathrm{PCR}) \geq 0.2$ who were being treated with $\mathrm{T}$. Losartan $50 \mathrm{mg} /$ day for $>2$ months.

The exclusion criteria were patients with extremes of ages, hypertensive emergency, severe diabetes mellitus, renal replacement therapy (dialysis and tansplant recipient patients) and history of heart failure, angina, myocardial infarction and stroke.

The subjects were then randomly assigned to 2 groups to receive either cilnidipine (10-20mg/day) or amlodipine (5$10 \mathrm{mg} /$ day). The drugs were given for a duration of 6 months for each patient. The dose of losartan $(50 \mathrm{mg} /$ day) was not adjusted throughout the study. At the time of randomization and at the end of 1, 3, 6 months spot urine protein creatinine ratio, serum creatinine, estimated glomerular filtation rate and blood pressure were determined. Spot urine PCR and serum creatinine were assessed using automated analyser. Estimated GFR was calculated by Modification of diet in renal disease (MDRD) study equation [ GFR $\left(\mathrm{ml} / \mathrm{min} / 1.73 \mathrm{~m}^{2}=175 \mathrm{x}\right.$ $\left(\mathrm{S}_{\mathrm{Cr}}\right)^{-1.154} \mathrm{x}(\text { Age })^{-0.203} \times(0.742$ if female $\left.)\right]$. The treatment compliance and safety variables were checked during each visit.

\section{Efficacy parameters}

The primary endpoint of the study was to assess the change in spot urine protein creatinine ratio from the baseline to the endpoint (at the end of 6 months). The secondary endpoints were to determine the changes in serum creatinine, estimated GFR and blood pressure from the baseline to the endpoint and to assess the progression/regression of CKD stages.

\section{Statistical analysis}

The baseline characteristics of both the groups were expressed as descriptive statistics. They were matched by unpaired student ' $t$ ' test and Pearson's chi-square test. For analysis and interpretation of variables within the group, student paired ' $t$ ' test and Wilcoxon Signed Rank test were used for normal and non normal data respectively. To compare the efficacy of the two drugs, unpaired ' $t$ ' test and Mann Whitney u test were carried out for normal and non normal data respectively. The categorical variables between the two groups were compared by Chi - square test of proportions. Statistical significance was set at $p$ $<0.05$.

\section{RESULTS}

Over the period of 1 year from April 2013 to May 2014, 100 patients with diabetic chronic kidney disease attending the outpatient Department of Nephrology with eligibility criteria were included in the study. The patients were then randomly assigned into 2 groups receiving either $\mathrm{T}$. Cilnidipine (Group A) or T. Amlodipine (Group B). Four patients in the cilnidipine group were withdrawn (1 patient due to adverse event; 2 patients due to poor BP control; 1 patient due to non compliance). There was no withdrawal in amlodipine group. Totally 96 patients completed the study and the results were statistically analysed. Figure 1 explains the flow of participants during the study.

\section{Baseline characteristics}

Table 1 summarizes the baseline characteristics of patients enrolled in the two groups. There was no statistical difference in the baseline parameters between cilnidipine and amlodipine group except for age (p-0.01) and urine protein creatinine ratio which was high in cilnidipine group (p-0.014). 


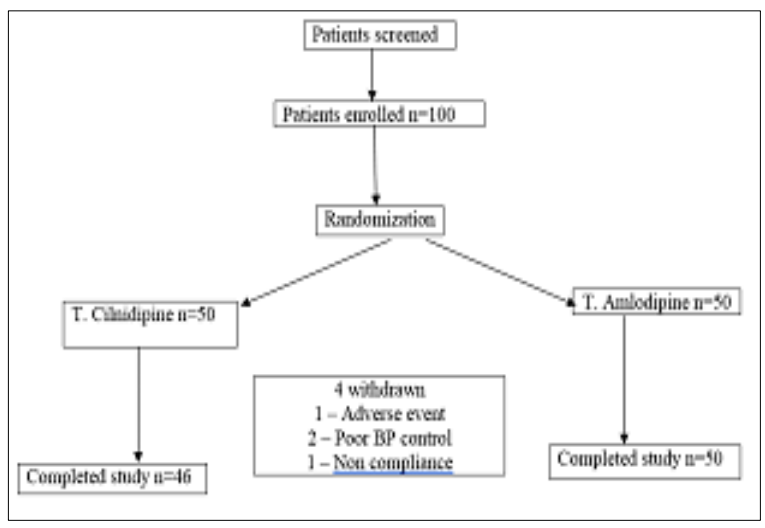

Figure 1: Flow of participants during the study.

\section{Changes in spot urine protein/Cr ratio (Urine PCR)}

As shown in Table 2, spot urine protein/Cr ratio was significantly lower in clnidipine group compared to amlodipine group at the end of 6 months $(1.09 \pm 0.72 \mathrm{vs}$ $1.40 \pm 0.65, \mathrm{p}<0.001)$. The reduction of urine PCR from baseline showed a significant difference between the 2 groups after 1 month of treatment and thereafter. However amlodipine group showed a decrease at the end of 3 months but the decrease was not sustained thereafter. At the end of 6 months, in amlodipine group urine PCR returned to baseline values. Thus after 6 months of treatment urine protein creatinine ratio had decreased in cilnidipine group but not in amlodipine group ( $-0.87 \pm 0.66$ vs $0.01 \pm 0.6, \mathrm{p}<0.001)$.

Table 1: Baseline characteristics.

\begin{tabular}{|c|c|c|c|c|}
\hline \multicolumn{2}{|c|}{$\begin{array}{l}\text { Baseline } \\
\text { parameters }\end{array}$} & $\begin{array}{l}\text { Cilnidipine } \\
\text { (mean) } \\
(n-46)\end{array}$ & $\begin{array}{l}\text { Amlodipine } \\
\text { (mean) } \\
(\mathbf{n}-50)\end{array}$ & $\begin{array}{l}p \\
\text { value }\end{array}$ \\
\hline \multicolumn{2}{|c|}{ Age (SD) } & $59.19(8.10)$ & $55.16(8.50)$ & 0.019 \\
\hline \multirow[t]{2}{*}{ Sex } & Male & 33 & 33 & \multirow{2}{*}{0.544} \\
\hline & Female & 13 & 17 & \\
\hline \multicolumn{2}{|c|}{ Urine PCR } & 1.94 & 1.38 & 0.014 \\
\hline \multicolumn{2}{|c|}{$\begin{array}{l}\text { Serum } \\
\text { creatinine }\end{array}$} & 3.13 & 2.75 & 0.158 \\
\hline \multicolumn{2}{|c|}{ eGFR } & 25.28 & 29.6 & 0.142 \\
\hline \multicolumn{2}{|c|}{ Systolic BP } & 149.13 & 148.40 & 0.779 \\
\hline \multicolumn{2}{|c|}{ Diastolic BP } & 92.17 & 90.8 & 0.461 \\
\hline \multicolumn{2}{|c|}{ Pulse rate } & 79.7 & 78.82 & 0.525 \\
\hline
\end{tabular}

\section{Changes in renal function}

Table 2 shows that the mean serum creatinine concentration increased progressively in both the groups. The difference in increase from baseline were equal in the two groups at the end of 6 months $(0.12 \pm 0.39$ vs $0.12 \pm 0.36, p=0.98)$. The estimated GFR also decreased in both the groups from baseline progressively but was not statistically significant both within and between the groups.

Table 2: Comparison of clinical parameters between cilnidipine and amlodipine group.

\begin{tabular}{|c|c|c|c|c|c|c|}
\hline \multirow{2}{*}{ Parameters } & \multirow{2}{*}{ Drug } & \multirow{2}{*}{ Baseline } & \multicolumn{2}{|l|}{3 months } & \multicolumn{2}{|l|}{6 months } \\
\hline & & & Values & P value & Values & P value \\
\hline \multirow{2}{*}{$\begin{array}{l}\text { Spot Urine } \\
\text { PCR }\end{array}$} & Cilnidipine & $1.94 \pm 1.22$ & $1.12 \pm 0.75$ & \multirow{2}{*}{$<0.001 *$} & $1.09 \pm 0.72$ & \multirow{2}{*}{$<0.001 *$} \\
\hline & Amlodipine & $1.38 \pm 0.98$ & $1.30 \pm 0.71$ & & $1.40 \pm 0.65$ & \\
\hline \multirow{2}{*}{$\begin{array}{l}\text { Serum } \\
\text { creatinine }\end{array}$} & Cilnidipine & $3.13 \pm 1.34$ & $3.22 \pm 1.46$ & \multirow{2}{*}{0.98} & $3.25 \pm 1.44$ & \multirow{2}{*}{0.98} \\
\hline & Amlodipine & $2.75 \pm 1.28$ & $2.84 \pm 1.25$ & & $2.87 \pm 1.28$ & \\
\hline \multirow{2}{*}{ eGFR } & Cilnidipine & $25.2 \pm 14.2$ & $24.6 \pm 13.3$ & \multirow{2}{*}{0.66} & $24.4 \pm 13.1$ & \multirow{2}{*}{0.65} \\
\hline & Amlodipine & $29.6 \pm 14.9$ & $27.8 \pm 14$ & & $27.6 \pm 13.9$ & \\
\hline \multirow{2}{*}{ Systolic BP } & Cilnidipine & $149.13 \pm 12.7$ & $126.52 \pm 13.6$ & \multirow{2}{*}{0.69} & $126.73 \pm 12.1$ & \multirow{2}{*}{0.21} \\
\hline & Amlodipine & $148.4 \pm 12.67$ & $124.8 \pm 11.1$ & & $122.6 \pm 14.5$ & \\
\hline \multirow{2}{*}{ Diastolic BP } & Cilnidipine & $92.17 \pm 8.4$ & $78.91 \pm 11$ & \multirow{2}{*}{0.84} & $79.35 \pm 7.7$ & \multirow{2}{*}{0.79} \\
\hline & Amlodipine & $90.8 \pm 9.6$ & $78 \pm 7.8$ & & $77.4 \pm 7.7$ & \\
\hline
\end{tabular}

*p value $<0.05$ statistically significant

\section{Changes in CKD stages}

Progression is defined as worsening by one stage and regression is improvement by one stage. The CKD stage was unchanged in 40 patients, progressed in 3 patients and regressed in 3 patients after treatment with cilnidipine and was unchanged in 36 patients, worsened in 8 patients and regressed in 6 patients in amlodipine treated group. Chi square test was done and it was found to be statistically insignificant $(\mathrm{p}=0.19)$ as shown in Table 3.

\section{Changes in blood pressure}

Table 2 shows the changes in systolic and diastolic BP. Both systolic and diastolic BP decreased significantly from baseline at the end of 1, 3 and 6 months in both the 
groups. No differences were observed between systolic BP $(126.73 \pm 12.1$ vs $122.6 \pm 14.5, \mathrm{p}=0.21)$ and diastolic BP $(79.35 \pm 7.7$ vs $77.4 \pm 7.7, p=0.79)$ in the patients in the two groups after 6 months.

Table 3: Changes in CKD stages.

\begin{tabular}{|llll|l|}
\hline Study & \multicolumn{3}{l}{ Changes in CKD stages } & P \\
group & Unchanged & Regression & Progression & $\begin{array}{l}\text { value } \\
\text { Cilnidipine }\end{array}$ \\
40 & 3 & 3 & 0.19 \\
\hline Amlodipine & 36 & 6 & 8 & \\
\hline
\end{tabular}

\section{Adverse effects}

Both the drugs were well tolerated. One patient was withdrawn from cilnidipine group at the start of the study due to non specific chest pain after 2 doses. But the ECG was within normal limits. Out of the 46 patients who completed the study in cilnidipine group, 6 (13\%) developed adverse effects. All the patients in amlodipine group completed the study among which 4 patients $(8 \%)$ developed adverse effects. All these adverse effects were mild and did not require discontinuation of drugs. (Table 4).

Table 4: Adverse drug reaction profile.

\begin{tabular}{|lll|}
\hline Adverse effects & Cilnidipine & Amlodipine \\
\hline Dizziness & 1 & 2 \\
\hline Peripheral EDEMA & 0 & 2 \\
\hline Increased appetite & 1 & 0 \\
\hline Increased blood sugar & 2 & 0 \\
\hline Itching & 1 & 0 \\
\hline Gastritis & 1 & 0 \\
\hline
\end{tabular}

\section{DISCUSSION}

Chronic kidney disease is a major risk factor for cardiovascular disease. In hypertensive patients with concomitant CKD, strict antihypertensive therapy is recommended. Antihypertensive therapy is primarily aimed at reducing proteinuria and blood pressure. The first line drugs in CKD are RAS inhibitors but most of the patients require multiple drugs to achieve blood pressure targets. In such cases, CCBs are more commonly used along with RAS inhibitors as they possess potent hypotensive effects. ${ }^{6}$ Several clinical trials have also suggested that treatment with $\mathrm{CCBs}$ and ARB/ACEI combination was more effective in preventing cardiovascular events. Hence the present study was performed to compare the combined effects of cilnidipine or amlodipine with losartan in patients with chronic kidney disease.

Many clinical studies have demonstrated that proteinuria is an important predictor of subsequent progression of kidney disease. Proteinuria is also directly associated with the risk of development of CAD. Thus, reduction in proteinuria protects against renal and cardiovascular failure. Recently, with regard to renal and cardiovascular outcomes in chronic kidney disease patients, antiproteinuric antihypertensive drugs are considered to be more beneficial. ${ }^{10}$

Proteinuria was assessed by urine protein creatinine ratio in our study. Random spot urine samples were used to determine UPCR. In a study conducted by Gai et al, it was demonstrated that urine protein creatinine ratio in spot urine sample correlated well with daily urine protein excretion. ${ }^{11}$ Either a first morning or a random spot urine sample can be obtained, as both are recommended by Kidney disease outcomes quality initiative of National kidney foundation. ${ }^{10}$

In the analysis of primary endpoint, patients treated with cilnidipine showed a steady decrease in urine protein creatinine ratio whereas in amlodipine group UPCR decreased at the end of 3 months but returned to baseline at the end of 6 months. The greater antiproteinuric effects of cilnidipine can be attributed to reduction in glomerular pressure caused by vasodilation of efferent arteriole due to blockade of N - Type calcium channel. Amlodipine being a predominant $\mathrm{L}$ type $\mathrm{CCB}$, does not have any effect on efferent arteriole due to absence of $\mathrm{L}$ type calcium channels and therefore glomerular pressure is not reduced. ${ }^{10}$ These results were consistent with Kyoto cilnidipine study and CARTER study which also reported that cilnidipine exhibited antiproteinuric effect greater than amlodipine. ${ }^{6,10}$

On analyzing the results of secondary endpoints, the serum creatinine increased in both the groups gradually. The increase of creatinine from baseline was almost equal in both the groups $(p=0.98)$. Estimated GFR was decreased from baseline in both the groups but the decrease was not statistically significant. Both cilnidipine and amlodipine maintained the renal function throughout the study period. Thus, by maintaining GFR both the drugs are expected to improve long term prognosis in CKD patients.

Strict BP control is another important parameter to prevent the progression of renal disease. Lowering of BP is also associated with significant fall in cardiovascular event. Both systolic and diastolic BP decreased significantly from baseline in both the groups at the end of 1,3 and 6 months. The reduction in blood pressure was equal in both the groups. Subjects with BP less than 130/80 accounted for $19 \%$ and $34 \%$ in cilnidipine and amlodipine groups respectively. Thus, both the drugs were equally efficacious in decreasing the BP and maintaining the reduction. But the percentage of patients who achieved the target BP goal was high in amlodipine group. As systemic blood pressure is directly transmitted to glomerular capillaries, amlodipine by causing a greater reduction in systemic blood pressure is expected to decrease glomerular pressure which might be attributed to its antiproteinuric effects seen in some patients in this study. 
Many studies have shown that higher heart rate is associated with long term risk of cardiovascular mortality independent of other risk factors. ${ }^{12}$ Pulse rate was maintained in both the groups in this current study. None of study drug produced reflex tachycardia. This result was similar to CARTER study in which heart rate was unaffected by both the drugs. ${ }^{10}$

In majority of patients, CKD stages were unaltered by both the drugs. Nearly 6 patients (12\%) improved in amlodipine group. Worsening of patients was less in cilnidipine compared to amlodipine group. But all these changes were statistically insignificant. Thus, distribution of CKD stages was similar between the two groups before and after treatment $(\mathrm{p}=0.19)$.

There were certain limitations in this study. First, since baseline urinary protein excretion showed a significant difference between the two groups the rate of change in urine protein creatinine by cilnidipine might be overestimated. Second, 24 hour urine collection is the gold standard test for assessment of urine protein excretion. But it might be difficult for the outpatients to give their cooperation and hence spot urine samples were used. Though spot urine sample may be a better alternative in clinical practice, still it carries some limitations. Third, it was an open label study and patients were followed up for short duration only. Hence long term Reno protective effects were not determined. Fourth, relationship between reduction in proteinuria and cardiovascular events were not assessed.

\section{CONCLUSION}

Cilnidipine has antihypertensive effect equivalent to amlodipine but addition of cilnidipine rather than amlodipine to losartan decreased urine protein excretion in diabetic chronic kidney disease patients. Therefore, combination therapy with cilnidipine and RAS inhibitor may be more beneficial and renoprotective in patients with diabetic chronic kidney disease.

\section{ACKNOWLEDGEMENTS}

Authors would like to thank J.B. Chemicals and Pharmaceuticals limited, Tirunelveli, Tamil Nadu, India for providing cilnidipine samples for the study.

Funding: No funding sources

Conflict of interest: None declared

Ethical approval: The study was approved by the Institutional Ethics Committee

\section{REFERENCES}

1. Longo, Fauci, Kasper. Harrison's principles of internal medicine. Mc Graw Hill publication; 18 ${ }^{\text {th }}$ Edition; Volume 2; chapter 280:2308-2326.
2. Remuzzi G, Schieppati A, Ruggenenti P. Nephropathy in patients with type 2 diabetes. $\mathrm{N}$ Engl J Med. 1997;346:1145-51.

3. National kidney foundation. K. DOQI clinical practice guidelines on hypertension and antihypertensive agents in chronic kidney disease. Am J Kidney Dis. 2004;43:S1-290.

4. Lavermann GD, Henning RH, De Jong PE, Navis G, Zeeuw D. Optimal Antiproteinuric dose of losartan in nondiabetic patients with nephritic range proteinuria. Am J Kidney Dis. 2001;38:1381-4.

5. Japanese Society of Hypertension. Japanese Society of Hypertension Guidelines for Management of Hypertension (JSH 2004). Hypertens Res. 2006;29:S1-S105.

6. Hakka T, Takeda K, Shiotsu Y, Sugishita C. Switching to an $\mathrm{L} / \mathrm{N}$ - type calcium channel blocker shows renoprotective effects in patients with chronic kidney disease: the Kyoto Cilnidipine study. The Journal of International Medical Research. 2012;40:1417-28.

7. Koshy S, Bakris GL. Therapeutic approaches to achieve desired blood pressure goals: focus on calcium channel blockers. Cardiovasc Drugs Ther. 2000;14:295-301.

8. Kloke HJ, Branten AJ, Huysmans FT, Wetzels JF. Antihypertensive treatment of patients with proteinuric renal diseases: risks or benefits of calcium channel blockers? Kidney International. 1998;53(6):1559-73.

9. Satomura A, Fujita T, Fuke Y, Wada Y, Matsumoto K. Change of Glomerular Hemodynamics in Patients with Advanced Chronic Kidney Disease after Cilnidipine Therapy. Open Clinical Chemistry Journal. 2009;2:31-6.

10. Fujita T, Ando K, Nishimura H. Antiproteinuric effect of the calcium channel blocker cilnidipine added to renin- angiotensin inhibition in hypertensive patients with chronic renal diseases. Kidney International. 2007;72:1543-9.

11. Gai M, Motta D, Giunti S, Fop F, Masini S, Mezza E, et al. Comparison between 24-h proteinuria, urinary protein/creatinine ratio and dipstick test in patients with nephropathy: Patterns of proteinuria in dipsticknegative patients. Scandinavian Journal of Clinical and Laboratory Investigation. 2006 Jan 1;66(4):299308.

12. Zaman ZA, Kumari V. Comparison of the effects of amlodipine and cilnidipine on blood pressure, heart rate, proteinuria and lipid profile in hypertensive patients. Int J Basic Clin Pharmacol. 2013;2:160-4.

Cite this article as: Maheswari YN, Meenakshi B, Ramasubramanian V, Ramya JE. Antiproteinuric effects of cilnidipine and amlodipine as add on therapy in hypertensive patients with chronic renal disease: a comparative study. Int J Basic Clin Pharmacol 2017;6:2482-6. 